\title{
Treatment of an impacted pancreatic duct stone by snare-assisted stone extraction and pancreatoscopy-guided lithotripsy
}

Ductal hypertension is regarded as one of the drivers of chronic pancreatitisrelated pain and has therefore been the main target of therapy. Although previous randomized controlled trials have supported surgical decompression, endoscopic therapy of symptomatic chronic pancreatitis has undergone a true revolution over the past decade [1]. The advent of digital single-operator pancreatoscopy (DSOP) and endoscopic ultrasound-guided pancreatic drainage have radically changed our endoscopic approach, which is now aimed at complete ductal clearance [2-4].

A 62-year-old patient with a history of smoking and alcohol abuse was referred to our center following chronic recurrent episodes of upper abdominal pain. Abdominal computed tomography revealed extensive calcifications in the head of the pancreas with an acute component of pancreatitis and a large obstructive, cylindrical stone (\$Fig.1). Intermittent discomfort persisted and magnetic resonance imaging showed clear retro-obstructive dilation of the main pancreatic duct (MPD), without signs of malignancy ( Fig.2). Owing to persisting symptoms and as the lesion proved unsuitable for extracorporeal shock wave lithotripsy, primary endoscopic treatment was proposed.

Under general anesthesia, the duodenoscope was introduced and showed an impacted stone at the level of the papilla ( Fig.3). Balloon extraction and MPD cannulation alongside the stone were attempted; both proved unsuccessful ( $\triangleright$ Video 1). As the impacted stone protruded into the duodenum, intraluminal electrohydraulic lithotripsy was deemed suboptimal. The decision was therefore made to extract the stone using a polypectomy snare. To improve traction, a right hemi-ampullectomy was required, after which the large MPD stone $(15 \times 8 \mathrm{~mm})$ was evacuated transorally ( Fig.4). DSOP-assisted electrohydrau-
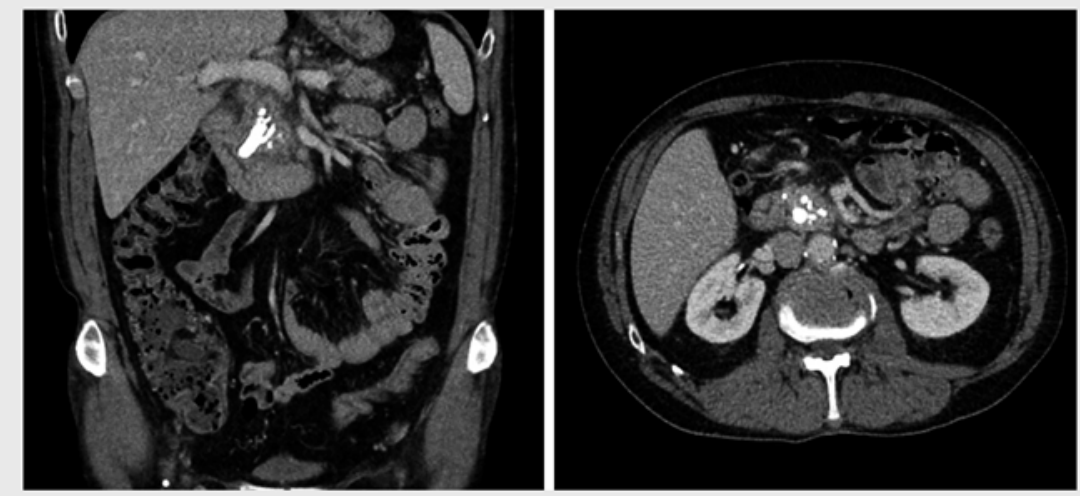

- Fig. 1 Abdominal computed tomography image, showing a large cylindrical stone with branching calcifications in the head of the pancreas.

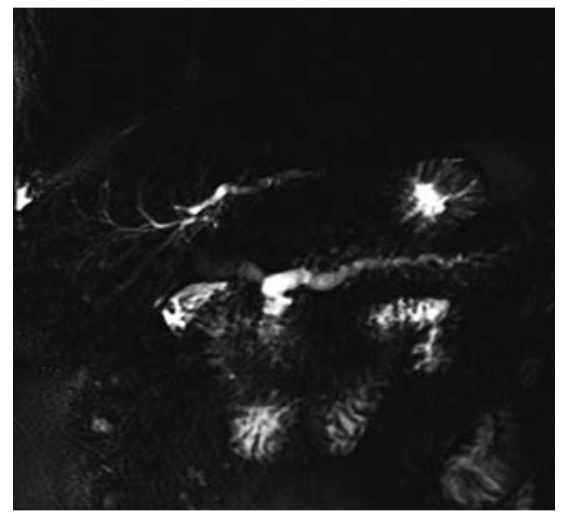

Fig. 2 Magnetic resonance imaging (T2 RARE sequence), confirming retroobstructive dilation of the main pancreatic duct, without clear signs of diffusionrestrictive neoplasia.

lic lithotripsy (> Fig.5), 6-mm balloon dilation, and stone extraction with a basket were performed without complications, followed by biliary $(60 \times 10 \mathrm{~mm}$ covered self-expandable metal stent) and MPD (8.5 Fr) stenting.

Our case illustrates the usefulness of snare-assisted treatment of impacted MPD stones, and highlights the multimodal treatment occasionally required to achieve complete ductal clearance.

Endoscopy_UCTN_Code_TTT_1AR_2AH

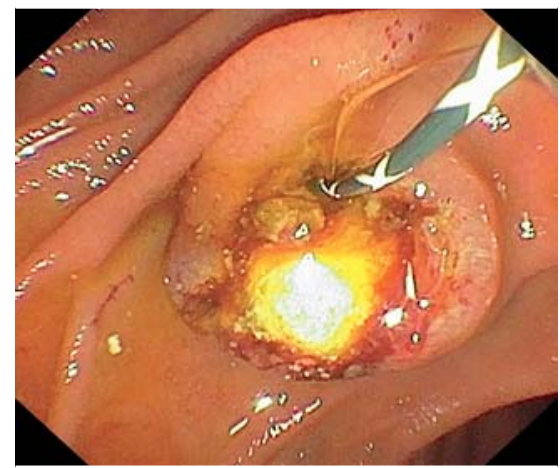

- Fig. 3 Side-viewing endoscopic image, revealing an impacted stone after successful biliary cannulation, which could not be mobilized using the biliary extraction balloon, nor were we able to cannulate the main pancreatic duct.

Competing interests

Michiel Bronswijk has received grants from Prion Medical, Taewoong, and Takeda, and has consultancy agreements with Prion Medical and Taewoong. Schalk van der Merwe holds the Cook and Boston-Scientific chair in interventional endoscopy and holds consultancy agreements with Cook, Pentax, and Olympus. Diederik Persyn and Philip Caenepeel declare that they have no conflict of interest. 


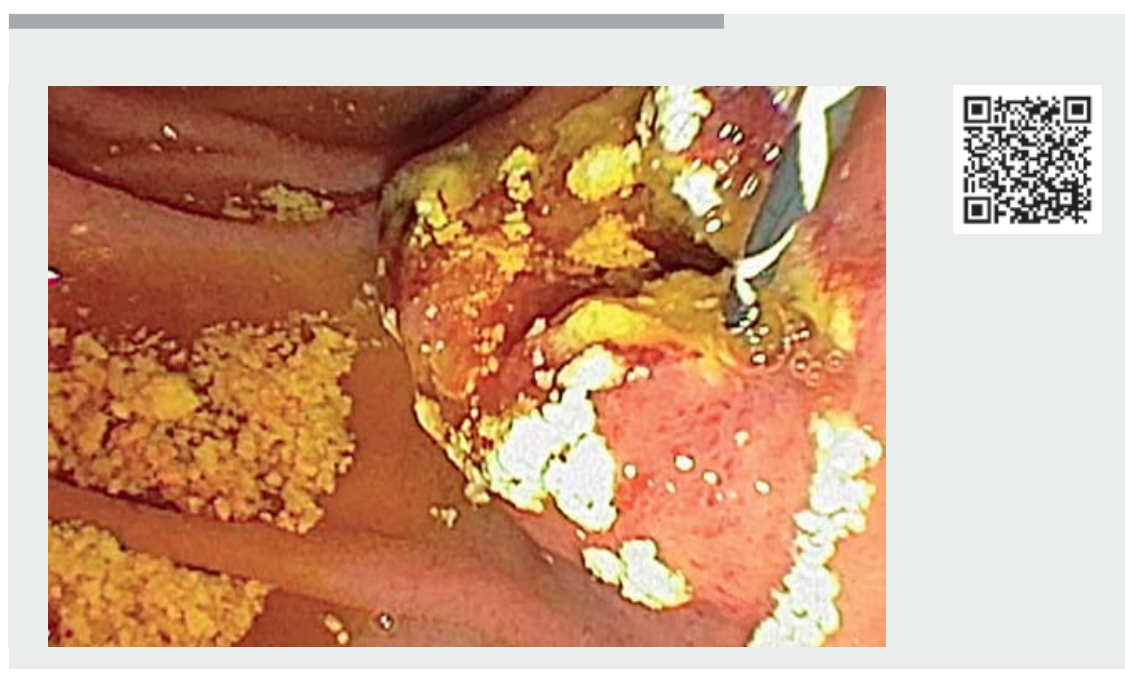

Video 1 Treatment of an impacted pancreatic duct stone by snare-assisted stone extraction and pancreatoscopy-guided lithotripsy.

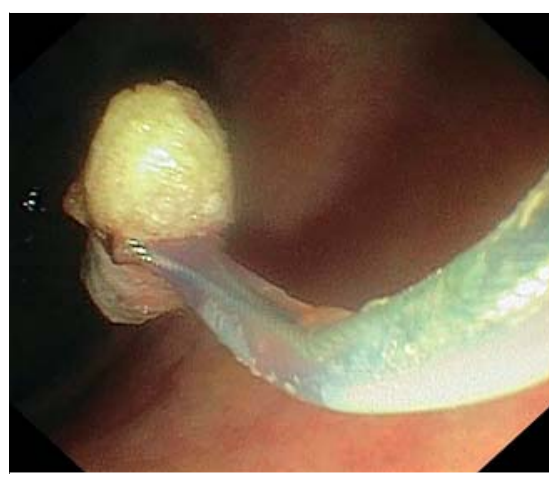

- Fig. 4 Endoscopic image following hemi-ampullectomy and snare-assisted stone extraction. A large cylindrical pancreatic stone was evacuated $(15 \times 8 \mathrm{~mm})$ and retrieved without complications.

The authors

Michiel Bronswijk ${ }^{1,2,3}$, Diederik Persyn²,4, Philip Caenepeel ${ }^{5}$, Schalk Willem Van der Merwe $^{2}$

1 Department of Gastroenterology, Imelda General Hospital, Bonheiden, Belgium

2 Department of Gastroenterology and Hepatology, University Hospitals Leuven, Belgium

3 Imelda Clinical GI Research Center, Bonheiden, Belgium

4 Department of Gastroenterology and Hepatology, AZ Damiaan, Oostende, Belgium

5 Department of Gastroenterology and Hepatology, Ziekenhuis Oost-Limburg, Genk, Belgium

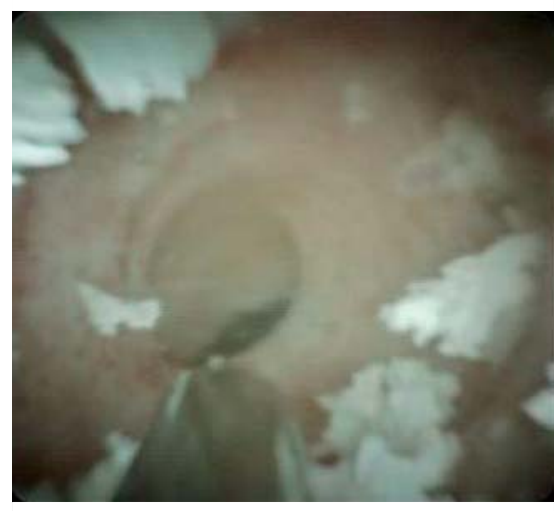

- Fig. 5 Digital pancreatoscopy image, showing successful main pancreatic duct recanalization after digital single-operator pancreatoscopy-guided electrohydraulic lithotripsy.

Corresponding author

\section{Michiel Bronswijk, MD}

Department of Gastroenterology and

Hepatology, University Hospitals Leuven, Leuven, Belgium

mjh.bronswijk@gmail.com

\section{References}

[1] Cahen DL, Gouma DJ, Nio Y et al. Endoscopic versus surgical drainage of the pancreatic duct in chronic pancreatitis. N Engl J Med 2007; 356: 676-684

[2] François E, Kahaleh M, Giovannini M et al. EUS-guided pancreaticogastrostomy. Gastrointest Endosc 2002; 56: 128-133
[3] Tessier G, Bories E, Arvanitakis M et al. EUSguided pancreatogastrostomy and pancreatobulbostomy for the treatment of pain in patients with pancreatic ductal dilatation inaccessible for transpapillary endoscopic therapy. Gastrointest Endosc 2007; 65: 233 241

[4] McCarty TR, Sobani Z, Rustagi T. Per-oral pancreatoscopy with intraductal lithotripsy for difficult pancreatic duct stones: a systematic review and meta-analysis. Endosc Int Open 2020; 8: E1460-E1470

\section{Bibliography}

Endoscopy 2022; 54: E344-E345

DOI 10.1055/a-1540-6319

ISSN 0013-726X

published online 19.7.2021

(c) 2021. Thieme. All rights reserved.

Georg Thieme Verlag KG, Rüdigerstraße 14, 70469 Stuttgart, Germany

\section{ENDOSCOPY E-VIDEOS \\ https://eref.thieme.de/e-videos}

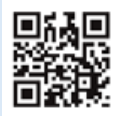

Endoscopy E-Videos is an open access online section, reporting on interesting cases and new techniques in gastroenterological endoscopy. All papers include a high quality video and all contributions are freely accessible online. Processing charges apply (currently EUR 375), discounts and wavers acc. to HINARI are available.

This section has its own submission website at 